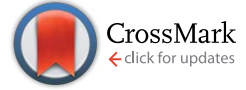

Cite this: J. Mater. Chem. A, 2016, 4, 7313

Received 6th March 2016

Accepted 30th March 2016

DOI: 10.1039/c6ta01945e

www.rsc.org/MaterialsA

\title{
Nitrogen-doped porous carbon nanosheets derived from poly(ionic liquid)s: hierarchical pore structures for efficient $\mathrm{CO}_{2}$ capture and dye removal $\dagger$
}

\begin{abstract}
Jiang Gong, Huijuan Lin, Markus Antonietti and Jiayin Yuan*
Poly(ionic liquid) has recently served as an important precursor for nitrogen-doped functional porous carbons. It was applied here in a facile one-pot approach to synthesize nitrogen-doped porous carbon nanosheets (NPCNSs) using $\mathrm{C}_{3} \mathrm{~N}_{4}$ nanosheets as sacrificial templates. $\mathrm{C}_{3} \mathrm{~N}_{4}$ nanosheets are found to improve the carbonization yield and nitrogen content of NPCNSs and additionally facilitate the formation of a unique pore structure. Without post-treatments or activation steps, the as-synthesized NPCNS readily reaches a specific surface area above $1100 \mathrm{~m}^{2} \mathrm{~g}^{-1}$ with hierarchical micro-/meso-/macropore structures while keeping a high nitrogen content (17.4 wt\%). More significantly, the NPCNS is able to deliver not only a high $\mathrm{CO}_{2}$ adsorption capacity with outstanding reversibility, but also an unprecedented capacity in methylene blue uptake by $962.1 \mathrm{mg} \mathrm{g}^{-1}$, which is among the few highest ever reported for wastewater, with excellent reusability.
\end{abstract}

\section{Introduction}

Nitrogen-doped porous carbon has received global interest and is still an increasingly expanding topic. ${ }^{1-8}$ This is ascribed to its unique, tunable physical and chemical properties at both atomic and macroscopic scales and a wide application scope in the fields of catalysis, ${ }^{\mathbf{9 - 1 3}}$ environmental remediation, ${ }^{\mathbf{1 4 - 1 8}}$ energy generation and storage, ${ }^{19-24}$ etc. It is believed that the doping of nitrogen atoms in the carbon framework not only adjusts the physical properties of the carbon material by increasing the overall electron density at the Fermi level while lowering the valence band position which improves the oxidation stability and electric conductivity, but also enhances the basicity of carbon to be highly active in catalysis. ${ }^{25-27}$ Tremendous efforts have heretofore been devoted in the past few years to preparing such carbons with a large specific surface area and high nitrogen content, which can be grouped into three general strategies. The first one is chemical or physical activation of existent nitrogen-doped carbon by acids (such as $\mathrm{H}_{3} \mathrm{PO}_{4}$ and

Department of Colloid Chemistry, Max Planck Institute of Colloids and Interfaces Am Mühlenberg 1 OT Golm, D-14476 Potsdam, Germany. E-mail: jiayin.yuan@mpikg. mpg.de

$†$ Electronic supplementary information (ESI) available: Surface element compositions of C-PIL and NPCNSs, the chemical structure of PIL, SEM and TEM images of $\mathrm{C}_{3} \mathrm{~N}_{4}$, the chemical structure of $\mathrm{MB}$, the zeta potential of $\mathrm{C}_{3} \mathrm{~N}_{4}$, XPS spectra of C-PIL and NPCNSs, the scheme of nitrogen elements, SEM images of C-PIL, reusability of NPCNS-10 for $\mathrm{CO}_{2}$ uptake, equilibrium adsorption isotherms of $\mathrm{MB}$ on $\mathrm{C}_{3} \mathrm{~N}_{4}$, reusability of NPCNS-10 for MB uptake. See DOI: 10.1039/c6ta01945e
$\mathrm{HNO}_{3}$ ), ${ }^{28,29}$ alkalis (such as $\mathrm{KOH}$ ), ${ }^{30-32}$ or other reagents (such as $\mathrm{CO}_{2}$ and $\left.\mathrm{H}_{2} \mathrm{O}\right)^{33,34}$ to etch the structure/graphitic layers, which facilitates majorly the formation of micropores. Usually, the usage of such harsh acids or alkalis could lead to structural corrosion, loss of intended nitrogen content and groups, and low product yields. The second strategy is the carbonization of a nitrogen-containing precursor in a template with a given nanostructure, such as mesoporous silica. ${ }^{35-39}$ Unfortunately, removal of the silica template by harmful chemicals such as $\mathrm{HF}$ or $\mathrm{NH}_{4} \mathrm{HF}_{2}$ is an unpleasant and legally restricted lab operation. The third strategy is post-treatment, such as thermal annealing in ammonia vapor $^{\mathbf{4 0}}$ or acetonitrile vapor, ${ }^{\mathbf{4 1}}$ to dope porous nitrogen-poor carbons with appropriate reactivity. This approach suffers from the need for additional vacuum facilities but especially they are very time- and energy-consuming procedures, which limit their application to the elaboration of principles. Consequently, developing easy, cost-effective sustainable approaches towards porous carbons with a large specific surface area and high nitrogen content is still an attractive goal to be pursued in many groups.

Since the first conversion of poly(ionic liquid)s (PILs) into graphitic, mesoporous and conductive carbon nanostructures in our group in $2010,{ }^{42}$ PILs have been proven to be a unique class of carbon precursors. ${ }^{\mathbf{4 3 4}}$ When comparing PILs over other polymers such as polypropylene, ${ }^{45}$ polyacrylonitrile, ${ }^{34}$ and poly(vinyl chloride) ${ }^{\mathbf{4 6}}$ as carbon precursors, the following advantages can be identified. Firstly, PILs are thermally stable at elevated temperatures even up to $400{ }^{\circ} \mathrm{C}$ and minimize the mass loss of the precursor at further heating due to the ionic 
nature. Secondly, many PILs contain incorporated/conjugated heteroatoms such as nitrogen or phosphorus in their molecular structures, thus favorably yielding heteroatoms in the final carbon products to tune physical properties and introduce active sites for catalyst design, as mentioned above. Thirdly, PILs are surface-active polymers which can serve as "universal coating" agents for diverse surfaces, say from metals over metal oxides to carbons. In other words, they are able to form homogeneous coatings or layers on most of the surfaces via a judicious choice of the backbone, anion and cation in their chemical structures. Accordingly, PIL-derived carbon materials with well-designed shapes and porous structures, including spheres, ${ }^{47,48}$ nanotubes, ${ }^{49}$ membranes, ${ }^{50}$ and monolithic objects with an inner structure ${ }^{51,52}$ have been prepared. The involved hard templating approaches such as using an $\mathrm{SiO}_{2}$ sphere ${ }^{47}$ and anodic aluminum oxide membrane ${ }^{49}$ give specific surface areas that are typically below $800 \mathrm{~m}^{2} \mathrm{~g}^{-1}$, which restrict their material performance. In addition, the morphology discussed here, nitrogen-doped porous carbon nanosheets (NPCNSs) have not yet been addressed via the PIL approach. It is well known that the coexistence of porous structures at various length scales combined with a large specific surface area will advantageously amplify the unusual benefit of nitrogen doping in carbon by accelerating the mass/energy transport to boost material performance..$^{3-55}$

Apart from using porous carbons in energy applications, environmental applications are of similar importance, especially because of the rich abundance and wide accessibility of a diversity of carbons. Two nearby cases driving the sustainable development of our modern society are greenhouse gas mitigation and wastewater treatment. ${ }^{56-59}$ Previous studies have pointed out that $\mathrm{CO}_{2}$ adsorption over carbon is closely related to its porosity and surface chemical state. ${ }^{60}$ Incorporating heteroatoms such as nitrogen into the carbon matrix has been demonstrated to enhance $\mathrm{CO}_{2}$ capture by virtue of the improved affinity between the active basic nitrogen sites and acidic $\mathrm{CO}_{2}$ molecules..$^{23,24}$ As for wastewater treatment, various synthetic dyestuffs appearing in the effluents of industries of plastics, dyes, paper, textiles and leather have caused severe environmental concerns. Although a wide variety of adsorbents have been employed for dye removal from wastewater, most of the reported adsorbents carry limited adsorption capacities for organic dyes. Exploiting new efficient adsorbents with high adsorption capacities is thereby one of the key tasks in water purification.

In this contribution, we report on a facile one-pot approach to synthesize NPCNSs using PILs as the precursor and carbon nitride $\left(\mathrm{C}_{3} \mathrm{~N}_{4}\right)$ nanosheets as sacrificial templates. Compared to the previous methods, the advantages of the current approach are easily visible. The synthesis of NPCNSs involves no posttreatments or activation steps in spite of employment of a template $\left(\mathrm{C}_{3} \mathrm{~N}_{4}\right.$ decomposes completely at around $600{ }^{\circ} \mathrm{C}$ under the formation of small nitrification agents). It will be shown that the NPCNSs exhibit a high $\mathrm{CO}_{2}$ adsorption capacity with outstanding reversibility and also that they are well-performing adsorbents for organic dyes.

\section{Experimental}

\subsection{Materials}

Poly[3-cyanomethyl-1-vinylimidazolium bis(trifluoromethanesulfonyl)imide] (PCMVImTf ${ }_{2} \mathrm{~N}$, simplified as "PIL", chemical structure shown in Fig. S1 in the ESI $\dagger$ ) was synthesized according to our previous method, ${ }^{61}$ and its apparent numberaverage molecular weight was measured to be $1.15 \times 10^{5} \mathrm{~g}$ $\mathrm{mol}^{-1}$ by gel permeation chromatography. The g- $\mathrm{C}_{3} \mathrm{~N}_{4}$ (simplified as $\mathrm{C}_{3} \mathrm{~N}_{4}$ ) nanosheets were prepared according to the previous work. ${ }^{62}$ In a typical run, $10.0 \mathrm{~g}$ of urea was first put into a crucible with a lid and then heated at $550{ }^{\circ} \mathrm{C}$ for $4 \mathrm{~h}$ at a heating rate of $4{ }^{\circ} \mathrm{C} \min ^{-1}$ in a muffle oven. Afterwards, light yellow $\mathrm{C}_{3} \mathrm{~N}_{4}$ nanosheets (morphology and microstructure displayed in Fig. S2 $\dagger$ ) were collected. Methylene blue (MB, chemical structure shown in Fig. S3†) was of analytical grade and supplied by Alfa Aesar. All other chemicals were of analytical grade.

\subsection{Preparation of the NPCNSs}

Firstly, $0.80 \mathrm{~g}$ of $\mathrm{C}_{3} \mathrm{~N}_{4}$ nanosheets were dispersed in tetrahydrofuran (THF) solution under vigorous agitation at room temperature for $6 \mathrm{~h}$ and subsequently sonicated for $6 \mathrm{~h}$ to obtain a homogeneous $\mathrm{C}_{3} \mathrm{~N}_{4}$ nanosheet suspension. Meanwhile, a defined amount of PIL was dissolved in THF. The $\mathrm{C}_{3} \mathrm{~N}_{4}$ nanosheet suspension and PIL solution were thoroughly mixed together in $\mathrm{C}_{3} \mathrm{~N}_{4} / \mathrm{PIL}$ mass ratio of 1,5 or 10 under vigorous agitation at room temperature for $6 \mathrm{~h}$ and then sonicated for $6 \mathrm{~h}$, followed by solvent evaporation at $70{ }^{\circ} \mathrm{C}$ to obtain light yellow $\mathrm{C}_{3} \mathrm{~N}_{4} / \mathrm{PIL}-x$ composites $(x=1,5$ or 10$)$. Afterwards, the composites were heated at $550{ }^{\circ} \mathrm{C}$ for $1 \mathrm{~h}$ at a heating rate of $10{ }^{\circ} \mathrm{C} \min ^{-1}$ under a nitrogen atmosphere and subsequently calcined at $750{ }^{\circ} \mathrm{C}$ for $1 \mathrm{~h}$ to degrade $\mathrm{C}_{3} \mathrm{~N}_{4}$ nanosheets. After cooling down to room temperature, a black powder was finally obtained and denoted as NPCNS-1, 5 or 10 . The carbon prepared from PIL in the absence of $\mathrm{C}_{3} \mathrm{~N}_{4}$ templates under the same fabrication process was denoted as C-PIL.

\subsection{Characterization}

Scanning electron microscopy (SEM) measurements were carried out in a LEO 1550-Gemini electron microscope (acceleration voltage $=3 \mathrm{kV}$ ), and the samples were coated with a thin gold layer before SEM measurements. Energy-dispersive X-ray (EDX) maps were taken on the SEM with an EDX spectrometer. The surface element compositions were characterized by means of X-ray photoelectron spectroscopy (XPS) carried out on a VG ESCALAB MK II spectrometer using $\mathrm{Al} \mathrm{K} \alpha$ exciting radiation from an X-ray source operated at $10.0 \mathrm{kV}$ and $10 \mathrm{~mA}$. Combustion elemental analyses were done with a varioMicro elemental analysis instrument from Elementar Analysensysteme. Transmission electron microcopy (TEM) measurements were performed using a Zeiss EM 912 (acceleration voltage $=120 \mathrm{kV}$ ). High-resolution TEM (HRTEM) measurements were carried out on a FEI Tecnai G2 S-Twin transmission electron microscope operating at $200 \mathrm{kV}$. X-ray diffraction (XRD) patterns were recorded on a Bruker D8 diffractometer using $\mathrm{Cu} \mathrm{K} \alpha$ radiation 
$(\lambda=0.154 \mathrm{~nm})$ and a scintillation counter. Raman spectroscopy (T6400, excitation-beam wavelength $=514.5 \mathrm{~nm}$ ) was used to characterize the vibrational properties of carbon materials. The surface electrical property of dispersed $\mathrm{C}_{3} \mathrm{~N}_{4}$ nanosheets in THF was evaluated on a zeta potential analyzer (Malvern Zetasizer Nano ZS90). Nitrogen sorption experiments were performed with a Quantachrome Autosorb and Quadrasorb at $77 \mathrm{~K}$, and the data were analyzed using Quantachrome software. The specific surface area was calculated using the BrunauerEmmett-Teller (BET) equation. The samples were degassed at $150{ }^{\circ} \mathrm{C}$ for $20 \mathrm{~h}$ before measurements.

\section{$2.4 \mathrm{CO}_{2}$ capture}

$\mathrm{CO}_{2}$ capture was accomplished by measuring the adsorption isotherms of the samples at $273 \mathrm{~K}$ in a Quantachrome Autosorb and Quadrasorb (Quantachrome Instruments). The samples were degassed at $150{ }^{\circ} \mathrm{C}$ for $20 \mathrm{~h}$ before measurements.

\subsection{Dye removal}

Adsorption experiments of MB using $\mathrm{C}_{3} \mathrm{~N}_{4}$, C-PIL or NPCNSs were carried out in a batch process by stirring $5.0 \mathrm{mg}$ of $\mathrm{C}_{3} \mathrm{~N}_{4}$, C-PIL or NPCNSs in $10.0 \mathrm{~mL}$ of MB solution in a $25 \mathrm{~mL}$ plastic flask. Working solution of MB was prepared from the stock solution $\left(1000 \mathrm{mg} \mathrm{L}^{-1}\right)$ to the designed concentration for each experimental run. After stirring for $180 \mathrm{~min}, 1.0 \mathrm{~mL}$ of $\mathrm{MB}$ solution was withdrawn using a syringe, filtered and diluted through a $0.25 \mu \mathrm{m}$ membrane for the later analysis of $\mathrm{MB}$ concentration. The absorbance of MB solution was measured using an UV/vis/NIR spectrophotometer (Lambda 900) to monitor the absorbance at $\lambda_{\max }=665 \pm 1 \mathrm{~nm}$, corresponding to the maximum absorbance. The concentration of MB solution was determined by a linear regression equation obtained by plotting the calibration curve for $\mathrm{MB}$ over a range of concentrations.

\section{Results and discussion}

Fig. 1 schematically illustrates the synthetic approach of NPCNSs using PIL as the precursor and $\mathrm{C}_{3} \mathrm{~N}_{4}$ nanosheets as sacrificial templates. A $\mathrm{C}_{3} \mathrm{~N}_{4} / \mathrm{PIL}-x$ composite with a different $\mathrm{C}_{3} \mathrm{~N}_{4} /$ PIL mass ratio ( $x=1,5$ and 10 ) was firstly obtained via mixing their suspension/solution in THF under sonication treatment. After the evaporation of THF, the composite was heated at $550{ }^{\circ} \mathrm{C}$ for $1 \mathrm{~h}$ and subsequently calcined at $750{ }^{\circ} \mathrm{C}$ for $1 \mathrm{~h}$ to convert PIL into carbon and simultaneously degrade the $\mathrm{C}_{3} \mathrm{~N}_{4}$ nanosheets. The resulting black powder was denoted as NPCNS- $x(x=1,5$ and 10), while the carbon prepared from PIL in the absence of $\mathrm{C}_{3} \mathrm{~N}_{4}$ templates under the same fabrication process was denoted as C-PIL.

Table 1 presents the carbonization yields of $\mathrm{C}_{3} \mathrm{~N}_{4}$, C-PIL and the three NPCNS samples obtained at different $\mathrm{C}_{3} \mathrm{~N}_{4} / \mathrm{PIL}$ mass ratios. Though $\mathrm{C}_{3} \mathrm{~N}_{4}$ itself has decomposed completely at $750{ }^{\circ} \mathrm{C}$ (yield $<0.1 \%$ ), when added to PIL, a higher carbonization yield of the $\mathrm{C}_{3} \mathrm{~N}_{4} /$ PIL- $x$ composite compared to that of pure PIL is observed. For example, the carbonization yield of pristine PIL is $21.7 \%$. In the case of the $\mathrm{C}_{3} \mathrm{~N}_{4} / \mathrm{PIL}-1$ composite, the yield is

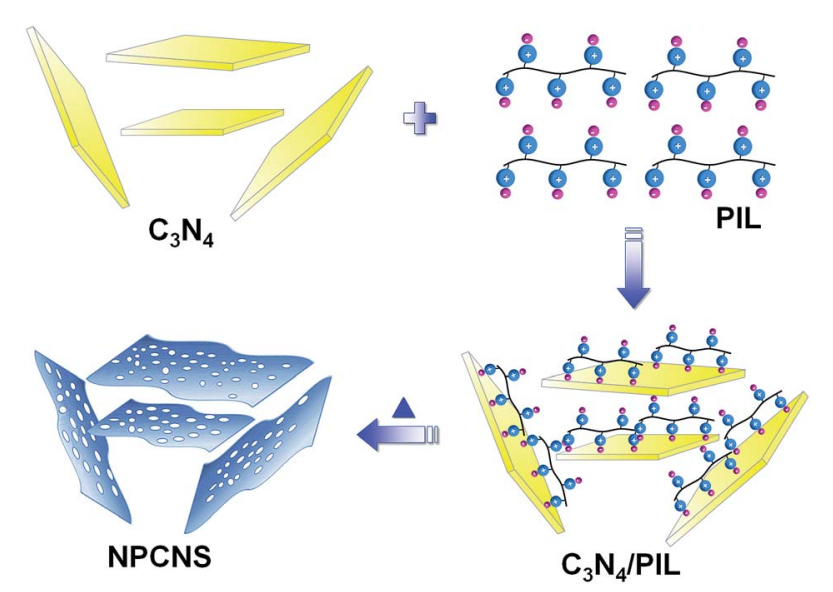

Fig. 1 Schematic illustration of NPCNS preparation using PIL as the precursor and $\mathrm{C}_{3} \mathrm{~N}_{4}$ nanosheets as sacrificial templates.

$24.4 \%$. By adding more $\mathrm{C}_{3} \mathrm{~N}_{4}$, even higher yields of $26.6 \%$ (NPCNS-5) and $30.0 \%$ (NPCNS-10) are received, respectively. A possible explanation is the reaction of the PIL condensates with the as-generated carbon nitride fragments via cycloaddition and biradical reactions. The surface of $\mathrm{C}_{3} \mathrm{~N}_{4}$ nanosheets has a negative charge, a value of about $-30 \mathrm{mV}$ determined by zeta potential measurement (Fig. S4 $\dagger$ ). The cationic PIL chains thus firmly attach to the surface of $\mathrm{C}_{3} \mathrm{~N}_{4}$ nanosheets via electrostatic complexation. The as-built Coulomb-stabilized interface layer with nanoscale mixing is expected to promote cross-reactions, and indeed such "confinement effects", were reported in several cases to enhance the carbonization yield. ${ }^{5,47,63}$

Combustion element analyses were carried out to access the element compositions of NPCNSs (Table 1). In general, the NPCNS products consist of carbon (65.4-69.7\%), nitrogen (14.9-17.4\%) and oxygen (10.5-17.8\%) with a trace amount of residual hydrogen (1.9-2.3\%). An enhanced nitrogen content is noticed when the PIL is carbonized in the presence of $\mathrm{C}_{3} \mathrm{~N}_{4}$. In the NPCNS-10 product, the nitrogen content is $17.4 \%$ and thereby a factor of 1.2 higher than that in the pure PIL-based sample. The improved carbonization yield as well as enhanced nitrogen content by mixing $\mathrm{C}_{3} \mathrm{~N}_{4}$ with PIL thus goes hand-inhand, both of which are favorable characters.

XPS measurements were conducted to further analyze surface element compositions and binding motifs of NPCNSs, which are important for adsorption. The results are summarized in Table S1. $\dagger$ Fig. S5 $\dagger$ shows the survey scan XPS spectra with apparent C 1s (284.6 eV), N 1s (398.6 eV) and O 1s (532.3 eV) peaks. The high-resolution N 1s XPS spectra are curve-fitted into four individual peaks (Fig. S6†): pyridinic $\mathrm{N}(398.2 \mathrm{eV})$, pyrrolic $\mathrm{N}$ (399.7 eV), graphitic N (400.7 eV), and oxidized N (402.8 eV), which follows the previous work. ${ }^{64}$ As displayed in Fig. 2, the quantitative analyses indicate that pyridinic $\mathrm{N}(49.9-51.7 \%)$ and graphitic $\mathrm{N}(29.8-31.3 \%)$ are the two most abundant $\mathrm{N}$ bonding schemes in the resultant NPCNSs.

The morphology of NPCNSs was visualized by SEM. It could be seen from Fig. 3a-f that the obtained NPCNSs appear as a continuous, interconnected 3D framework of nanosheets of diverse size with pores at different length scales. A large number 
Table 1 Yields, element compositions, and textural parameters of $\mathrm{C}_{3} \mathrm{~N}_{4}, \mathrm{C}$-PIL and NPCNSs

\begin{tabular}{lllllrrr}
\hline Sample & Yield $^{a}(\%)$ & $\mathrm{C}^{b}(\%)$ & $\mathrm{N}^{b}(\%)$ & $\mathrm{H}^{b}(\%)$ & $\mathrm{O}^{c}(\%)$ & $S_{\mathrm{BET}^{d}\left(\mathrm{~m}^{2} \mathrm{~g}^{-1}\right)}$ & $V^{e}\left(\mathrm{~cm}^{3} \mathrm{~g}^{-1}\right)$ \\
\hline $\mathrm{C}_{3} \mathrm{~N}_{4}$ & $<0.1$ & 35.1 & 60.6 & 2.0 & 2.3 & 97.0 & 0.101 \\
C-PIL & 21.7 & 64.7 & 14.5 & 2.2 & 18.6 & 707.6 & 0.382 \\
NPCNS-1 & 24.4 & 65.4 & 14.9 & 1.9 & 17.8 & 723.5 & 1.420 \\
NPCNS-5 & 26.6 & 67.7 & 15.8 & 2.1 & 14.4 & 965.2 & 1.620 \\
NPCNS-10 & 30.0 & 69.8 & 17.4 & 2.3 & 10.5 & 1120.0
\end{tabular}

${ }^{a}$ Calculated by the mass ratio of the obtained carbon to its precursor. ${ }^{b}$ Measured by combustion element analyses. ${ }^{c}$ Calculated by the difference. ${ }^{d}$ The BET specific surface area. ${ }^{e}$ Total volume of the pore.
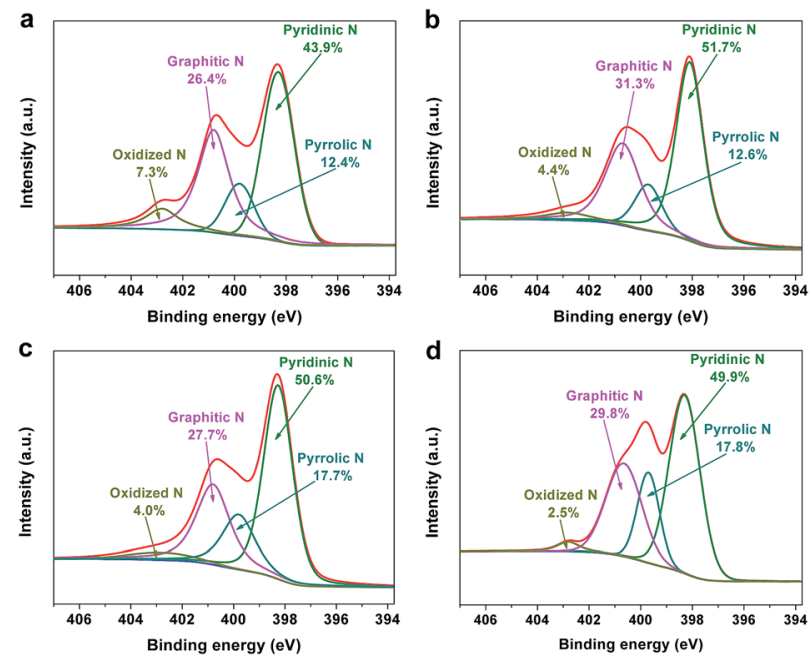

Fig. 2 High-resolution N 1s XPS spectra of (a) C-PIL, (b) NPCNS-1, (c) NPCNS-5, and (d) NPCNS-10.

of disordered macropores built up from irregular curving and stacking of nanosheets are observed (Fig. 3b, $d$ and f), which are evidently different from that of the reference sample C-PIL being composed of small dense nanoparticles (Fig. S7 $\dagger$ ). EDX maps of carbon, nitrogen and oxygen in the NPCNS-10 (Fig. 3gi) confirm that the samples are uniform with respect to element

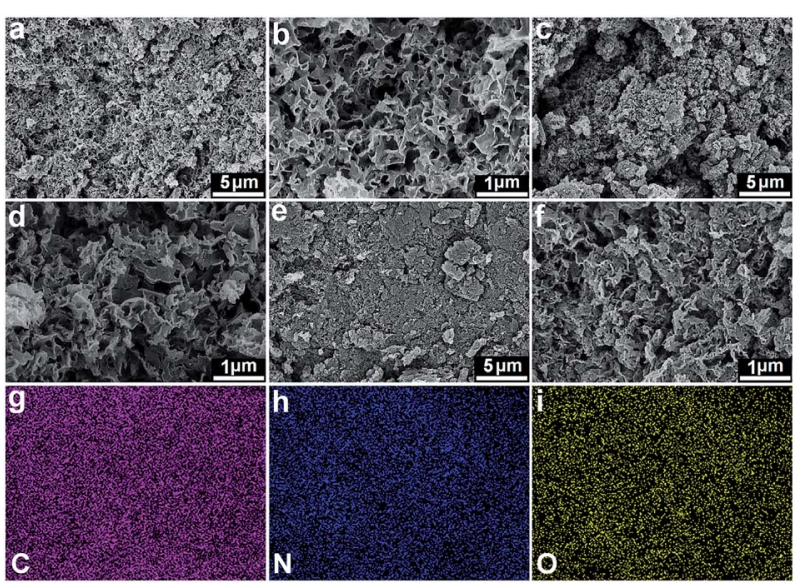

Fig. 3 SEM images of (a and b) NPCNS-1, (c and d) NPCNS-5, and (e and f) NPCNS-10. EDX maps of (g) C, (h) N, and (i) O elements for NPCNS-10 according to the corresponding SEM image (f). distribution. The local structure of NPCNSs was further analyzed by TEM. As shown in Fig. 4a-c, NPCNSs consist of randomly aggregated, entangled graphene-like carbon nanosheets, the thickness of which ranges from several to a dozen of nanometers. A notable structural feature of these carbon nanosheets is the existence of crimples along the surface. HRTEM was conducted to highlight the subnanometer structure of NPCNS-10 (Fig. 4d). The dark parallel patterns (white arrows) are stacked graphene layers with short-range order on the local scale, indicating a partial orientation of graphite crystallites. From the above results, it can be concluded that $\mathrm{C}_{3} \mathrm{~N}_{4}$ nanosheets as templates have a profound impact on the morphology of the NPCNSs, as they obviously direct the carbonization from random connectivities to a hierarchically organized structural motif.

XRD measurements were employed to additionally characterize the local order of NPCNSs. As depicted in Fig. 5a, the appearance of a broad and weak diffraction peak at $2 \theta=26.1^{\circ}$, which is assigned to the typical graphitic (002) plane, confirms the restricted stacking of the as-found graphene sheets. Raman spectroscopy (Fig. 5b) complements these observations: the $\mathrm{G}$ band at about $1580 \mathrm{~cm}^{-1}$ and $\mathrm{D}$ band at about $1350 \mathrm{~cm}^{-1}$ are relevant to the ordered carbon structure with the $\mathrm{sp}^{2}$ electronic configuration, and the disordered/defective structure of carbon, respectively. The intensity ratio of the $\mathrm{G} / \mathrm{D}$ band $\left(I_{\mathrm{G}} / I_{\mathrm{D}}\right)$ is usually
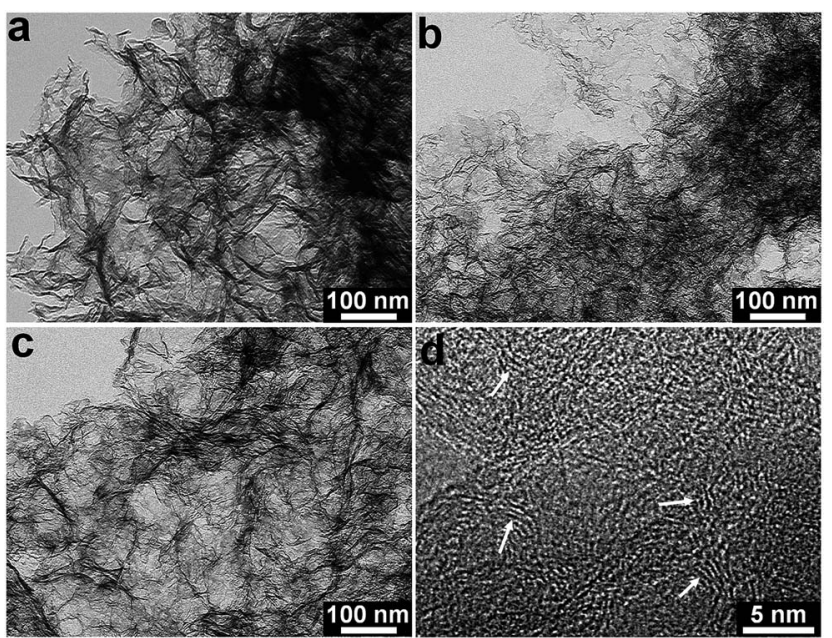

Fig. 4 TEM images of (a) NPCNS-1, (b) NPCNS-5, and (c) NPCNS-10, and (d) HRTEM image of NPCNS-10. 

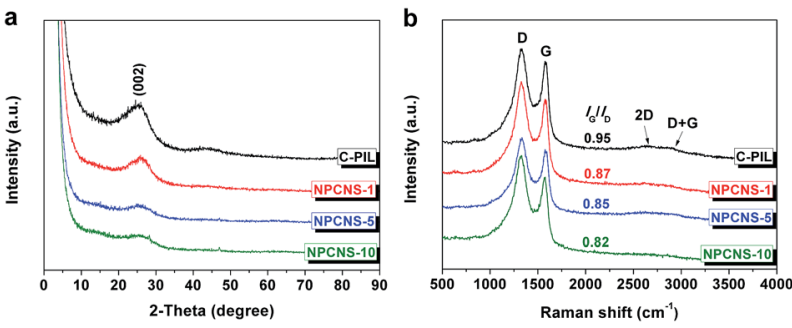

Fig. 5 XRD patterns (a) and Raman spectra (b) of C-PIL and NPCNSs.

utilized to estimate the degree of graphitization, but is of course also massively influenced by the nitrogen content and the coupled molecular pores and edge terminations. With increasing the $\mathrm{C}_{3} \mathrm{~N}_{4} / \mathrm{PIL}$ mass ratio, the $I_{\mathrm{G}} / I_{\mathrm{D}}$ value of the resultant carbon products is reduced from 0.95 to 0.82 . Besides, the rather weak $2 \mathrm{D}$ band at about $2660 \mathrm{~cm}^{-1}$ and $\mathrm{D}+\mathrm{G}$ band at about $2880 \mathrm{~cm}^{-1}$ verify the low longer range regularity of the material at $750{ }^{\circ} \mathrm{C}$.

Nitrogen adsorption/desorption measurements were carried out at $77 \mathrm{~K}$ to analyze the textural properties of $\mathrm{C}_{3} \mathrm{~N}_{4}$, C-PIL and NPCNSs. The results including the Brunauer-Emmett-Teller specific surface area $\left(S_{\mathrm{BET}}\right)$ and pore volume $(V)$ are summarized in Table 1. As displayed in Fig. $6 \mathrm{a}$ and $\mathrm{b}, \mathrm{C}_{3} \mathrm{~N}_{4}$ nanosheets as such are poorly porous, bearing a small $S_{\mathrm{BET}}$ value of $97.0 \mathrm{~m}^{2}$ $\mathrm{g}^{-1}$ and low $V\left(0.101 \mathrm{~cm}^{3} \mathrm{~g}^{-1}\right)$. As a second reference sample, C-PIL prepared from PIL alone presents a combined type I/IV physisorption isotherm. A high adsorption capacity at low relative pressure $\left(P / P_{0}<0.1\right)$ is observed, which reveals the significant presence of micropores in the C-PIL. The detectable type- $\mathrm{H} 4$ hysteresis loop at the relative pressure $P / P_{0}$ ranging from 0.4 to 0.8 corresponds to the filling and emptying of a small fraction of mesopores by capillary condensation. The formation mechanism of the micro/mesopores is believed to be similar to that reported by Dai et al. ${ }^{65}$ They found that the cyano
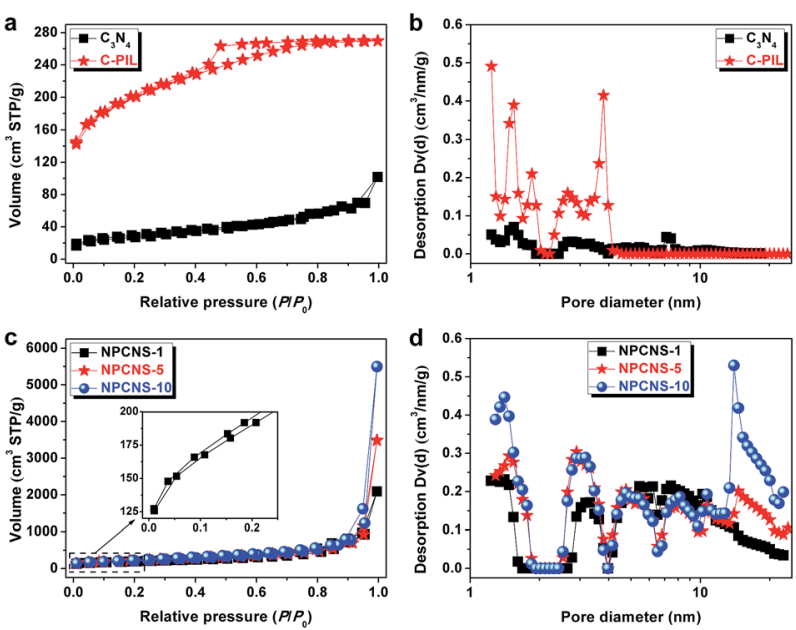

Fig. 6 Nitrogen adsorption/desorption isotherms and pore size distributions of ( $a$ and $b$ ) C-PIL and $\mathrm{C}_{3} \mathrm{~N}_{4}$ and (c and d) the three NPCNS products. (Inset) Nitrogen adsorption/desorption isotherms of NPCNS-1 in the low relative pressures. groups in the chemical structure of the ILs underwent trimerization reaction at medium temperatures $\left(350-450{ }^{\circ} \mathrm{C}\right)$, first producing a solid triazine-based polymeric network. The largesized anions (Fig. S1 $\dagger$ ) were trapped and aggregated in the matrix, and left behind the pores via the subsequent volatilization of this entity. The $S_{\mathrm{BET}}$ and $V$ of C-PIL are determined to be $707.6 \mathrm{~m}^{2} \mathrm{~g}^{-1}$ and $0.382 \mathrm{~cm}^{3} \mathrm{~g}^{-1}$, respectively.

The adsorption/desorption isotherms of NPCNSs obtained at different $\mathrm{C}_{3} \mathrm{~N}_{4} / \mathrm{PIL}$ mass ratios follow the type IV isotherm with a weak $\mathrm{H} 3$ hysteresis loop (Fig. 6c), which goes very well with the layered nanostructure, surface adsorption onto these entities and a weak occurrence of slit-pores between carbon nanosheets. The hysteresis loops of NPCNSs occur at low relative pressure $\left(P / P_{0}<0.1\right)$ characterizing the long slit-like micropores to have a microporous character, with a slit distance of $1.1 \mathrm{~nm}$. All the rest of the curve is typical for strong surface adsorption along delaminated carbon sheets, i.e., complying well with the structural features of the sample. Particularly, with the increasing $\mathrm{C}_{3} \mathrm{~N}_{4} / \mathrm{PIL}$ mass ratio from 0,1 and 5 to 10 , the $S_{\text {BET }}$ and $V$ increase from 707.6, 723.5 and 965.2 to $1120.0 \mathrm{~m}^{2} \mathrm{~g}^{-1}$, and from $0.382,1.420$ and 1.620 to $2.280 \mathrm{~cm}^{3} \mathrm{~g}^{-1}$, respectively. Here, by framing with more $\mathrm{C}_{3} \mathrm{~N}_{4}$, the $S_{\mathrm{BET}}$ value steadily increases and exceeds $1100 \mathrm{~m}^{2} \mathrm{~g}^{-1}$. This is straightforward to understand: a relatively lower amount of PILs means a thinner surface layer on the templates and thereby a lower structural density. Combining those values with the even larger macropores observed in the SEM characterization (Fig. 3), it proves that $\mathrm{C}_{3} \mathrm{~N}_{4}$ nanosheets promote the desirable formation of a hierarchical sorption system in NPCNSs, where the slit pores and the graphitic sheet surfaces provide a high contact surface area, while the larger pores (macropores and large mesopores) highspeed transport channels.

Based on the above-mentioned analyses, without post-treatments or activation steps, NPCNSs possessing a large specific surface area with hierarchical pore structures and high nitrogen
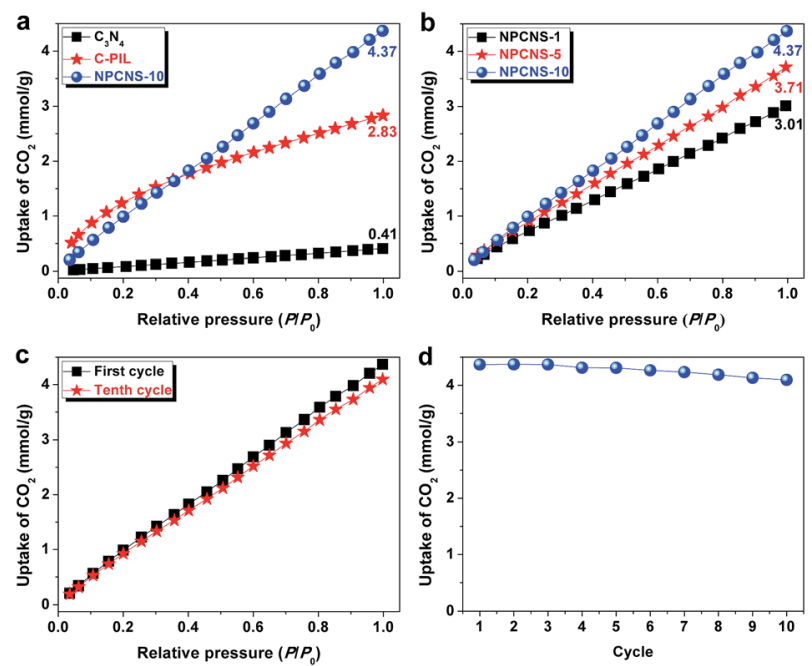

Fig. 7 ( $a$ and b) $\mathrm{CO}_{2}$ adsorption isotherms of $\mathrm{C}_{3} \mathrm{~N}_{4}, \mathrm{C}-\mathrm{PIL}$, and NPCNSs measured at $273 \mathrm{~K}$. (c) $\mathrm{CO}_{2}$-multicircle-adsorption isotherms of NPCNS-10 measured at $273 \mathrm{~K}$. (d) The reusability of NPCNS-10 for $\mathrm{CO}_{2}$ uptake at $273 \mathrm{~K}$. 
Table 2 Comparison of the $\mathrm{CO}_{2}$ uptake at $273 \mathrm{~K}$ among various adsorbents

\begin{tabular}{llll}
\hline Entry & Sample & $\mathrm{CO}_{2}$ uptake $\left(\mathrm{mmol}^{-1}\right)$ & \\
\hline 1 & N-Doped microporous carbon & 2.65 & 66 \\
2 & Microporous carbonaceous material & 2.28 & 67 \\
3 & Microporous conjugated polymer & 3.0 & 68 \\
4 & Microporous organic polymer & 3.47 & 69 \\
5 & Covalent organic framework & 3.95 & 70 \\
6 & Hollow octahedral carbon cage & 4.0 & 72 \\
7 & Sulfone-DUT-5 metal organic framework & 4.0 & 17 \\
8 & N-Doped carbon monolith & 4.2 & 73 \\
9 & Well-defined microporous carbon & 4.28 & 74 \\
10 & Porous carbon nanosheet & 4.3 & \\
11 & NPCNS-10 & 4.37 & \\
12 & Hierarchically porous carbon & 4.6 & \\
\end{tabular}

content are synthesized from PIL through a facile one-pot sustainable approach. To exemplify potential applications, we now analyze their use in $\mathrm{CO}_{2}$ capture and organic dye removal from wastewater. Fig. 7a presents the $\mathrm{CO}_{2}$ adsorption isotherms measured at $273 \mathrm{~K}$ for $\mathrm{C}_{3} \mathrm{~N}_{4}$, C-PIL and NPCNSs, respectively. Remarkably, NPCNS-10 shows the desired unusually high capacity of $4.37 \mathrm{mmol} \mathrm{g}^{-1}$ at $273 \mathrm{~K}$, obviously superior to those of $\mathrm{C}_{3} \mathrm{~N}_{4}\left(0.41 \mathrm{mmol} \mathrm{g}^{-1}\right)$ and C-PIL (2.83 $\left.\mathrm{mmol} \mathrm{g}^{-1}\right)$, a natural outcome of high specific surface area, large pore volume, combined pore sizes and high nitrogen content (especially the pyridinic $\mathrm{N}$ and pyrrolic $\mathrm{N}$ since they act as Lewis bases and readily interact with the acidic $\mathrm{CO}_{2}$ molecules ${ }^{23,24}$ ) in the NPCNS10. Furthermore, the $\mathrm{CO}_{2}$ adsorption capacities of NPCNS- 1 and NPCNS-5 (Fig. 7b) are measured to be 3.01 and $3.71 \mathrm{mmol} \mathrm{g}^{-1}$, respectively, which as expected are lower than that of NPCNS-10, but still among the better values found in the literature. Compared to other $\mathrm{CO}_{2}$ adsorbents (Table 2), including $\mathrm{N}$-doped microporous carbon, ${ }^{66}$ microporous carbonaceous material, ${ }^{67}$ microporous conjugated polymer, ${ }^{68}$ microporous organic polymer, ${ }^{69}$ covalent organic framework, ${ }^{70}$ hollow octahedral carbon cage, ${ }^{71}$ sulfone-DUT-5 metal organic framework, ${ }^{72} \mathrm{~N}$-doped carbon monolith, ${ }^{17}$ well-defined microporous carbon, ${ }^{73}$ porous carbon nanosheet, ${ }^{74}$ and hierarchically porous carbon, ${ }^{18}$ NPCNS10 is among the top-performers for $\mathrm{CO}_{2}$ capture.

Besides, the reversibility of $\mathrm{CO}_{2}$ adsorption on NPCNS-10 is tested over 10 cycles (Fig. 7c), after which a value of $4.01 \mathrm{mmol}$ $\mathrm{g}^{-1}$ remains (Fig. 7d). This is approximately $92 \%$ of the original adsorption capacity. We assume that the other $8 \%$ are then blocked by other ordinary higher boiling-point impurities, e.g., water, but this capacity can be regained via regeneration treatment after many cycles (Fig. S8 $\dagger$ ). It is worth pointing out that as an absorbent NPCNS-10 is better than aqueous amine and amine-functionalized solids, for which large amounts of energy are often required for the regeneration. ${ }^{60}$ Additionally, thermal stability is another merit of NPCNS-10 than the organic counterparts. From this standpoint, it is allowed to state that NPCNS10 displays satisfactory $\mathrm{CO}_{2}$ capture performance with outstanding reversibility under ambient conditions.

The equilibrium isotherm describes how the adsorbate interacts with the adsorbent, and the correlation of experimental results to an adsorption model is helpful to understand the adsorption mechanism. A Langmuir model is applied to analyze the relationship between the equilibrium adsorption capacity $\left(q_{\mathrm{e}}, \mathrm{mg} \mathrm{g}^{-1}\right)$ of $\mathrm{MB}$ (which is considered as one of the major water contaminants in surface water and groundwater) on the NPCNSs and its equilibrium solute concentration $\left(C_{\mathrm{e}}\right.$, $\mathrm{mg} \mathrm{L}^{-1}$ ) as follows:

$$
q_{\mathrm{e}}=q_{\mathrm{m}} K_{\mathrm{L}} C_{\mathrm{e}} /\left(1+K_{\mathrm{L}} C_{\mathrm{e}}\right)
$$

where $K_{\mathrm{L}}$ is the Langmuir constant $\left(\mathrm{L} \mathrm{mg}^{-1}\right)$ and $q_{\mathrm{m}}$ is the maximum adsorption capacity $\left(\mathrm{mg} \mathrm{g}^{-1}\right)$ relating to the complete monolayer covering of $\mathrm{MB}$, depending on the number of adsorption sites.

Fig. 8a and $\mathrm{S} 9 \dagger$ show the equilibrium adsorption isotherms of $\mathrm{MB}$ on the $\mathrm{C}_{3} \mathrm{~N}_{4}$, C-PIL and NPCNS-10. The amount of
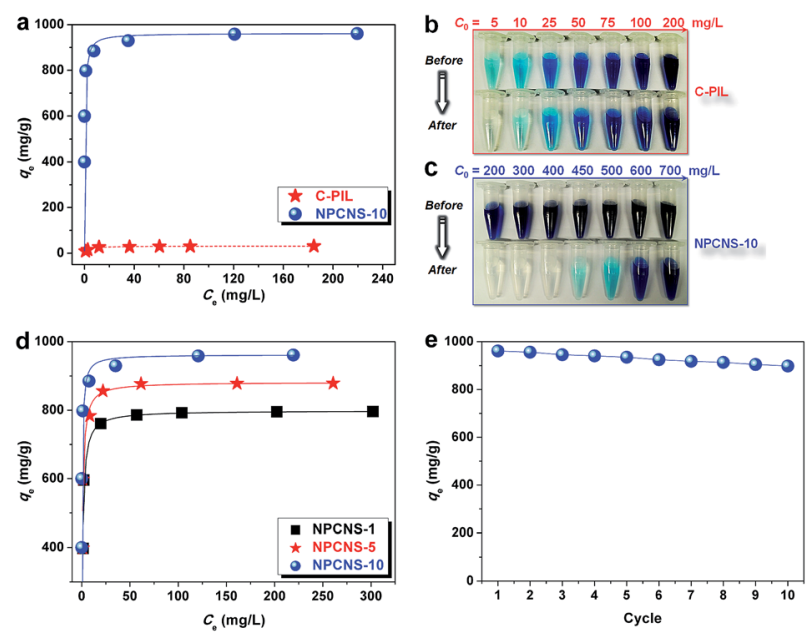

Fig. 8 (a) Equilibrium adsorption isotherms of MB on the C-PIL and NPCNS-10 (experimental conditions: $M B$ initial concentration $\left(C_{0}\right)=$ 5-200 $\mathrm{mg} \mathrm{L}^{-1}$ for C-PIL or 200-700 $\mathrm{mg} \mathrm{L}^{-1}$ for NPCNS-10, and C-PIL or NPCNS-10 concentration $=0.5 \mathrm{~g} \mathrm{~L}^{-1}$ ). The corresponding photographs of MB solutions before and after adsorption by (b) C-PIL or (c) NPCNS-10. (d) Equilibrium adsorption isotherms of MB on the NPCNSs (experimental conditions: $C_{0}=200-700 \mathrm{mg} \mathrm{L}^{-1}$ and NPCNS concentration $=0.5 \mathrm{~g} \mathrm{~L}^{-1}$ ). (e) Reusability of NPCNS-10 for the adsorption of MB (experimental conditions: $C_{0}=700 \mathrm{mg} \mathrm{L}^{-1}$ and NPCNS-10 concentration $=0.5 \mathrm{~g} \mathrm{~L}^{-1}$ ). 
Table 3 Langmuir isotherm parameters of $\mathrm{C}_{3} \mathrm{~N}_{4}, \mathrm{C}$-PIL and NPCNSs

\begin{tabular}{llllll}
\hline Parameter & $\mathrm{C}_{3} \mathrm{~N}_{4}$ & C-PIL & NPCNS-1 & NPCNS-5 & NPCNS-10 \\
\hline$q_{\mathrm{m}}\left(\mathrm{mg} \mathrm{g}^{-1}\right)$ & 25.1 & 31.2 & 798.7 & 818.8 & 962.1 \\
$K_{\mathrm{L}}\left(\mathrm{L} \mathrm{mg}^{-1}\right)$ & 0.31 & 0.33 & 1.03 & 1.30 & 2.50 \\
$R^{2}$ & 0.9995 & 0.9997 & 0.9996 & 0.9995 & 0.9993 \\
\hline
\end{tabular}

adsorbed MB dramatically increases at a low final solution concentration, suggesting a high affinity between MB molecules and the NPCNS-10 surface. Subsequently, the adsorbed amount quickly reaches a plateau at a high equilibrium solution concentration, reflecting the saturation of adsorption. As displayed in Table 3, the $R^{2}$ value exceeds 0.999, i.e., the experimental results could be well fitted using the Langmuir model. Strikingly, the $q_{\mathrm{m}}$ of NPCNS-10 for MB is as high as $962.1 \mathrm{mg}$ $\mathrm{g}^{-1}$, which is more than 30 times higher than that of C-PIL $\left(31.2 \mathrm{mg} \mathrm{g}^{-1}\right)$ or $\mathrm{C}_{3} \mathrm{~N}_{4}\left(25.1 \mathrm{mg} \mathrm{g}^{-1}\right)$. Though C-PIL $\left(S_{\mathrm{BET}}=707.6\right.$ $\mathrm{m}^{2} \mathrm{~g}^{-1}$ ) has a much higher specific surface area than that of $\mathrm{C}_{3} \mathrm{~N}_{4}\left(S_{\mathrm{BET}}=97 \mathrm{~m}^{2} \mathrm{~g}^{-1}\right)$, its adsorption capacity is only comparable to $\mathrm{C}_{3} \mathrm{~N}_{4}$, as the rather small micropores of C-PIL suffer from being non-accessible. The superior MB adsorption capacity of NPCNS-10 is not only owing to its high specific surface area, but also its large pore volume, as well as a high relative contribution of the outer surface area and high nitrogen content. Hydrogen bonding interaction (e.g., the nitrogen atom of a pyridinic $\mathrm{C}-\mathrm{N}$ group can serve as a hydrogen-bonding acceptor) and $\pi-\pi$ interaction (since MB is a planar molecule, see Fig. S3 $\uparrow)^{75,76}$ between MB and NPCNS-10 stimulate the rather high binding already at low dye concentrations.

More significantly, compared to the previously reported $\mathrm{MB}$ adsorbents (Table 4), such as the $\mathrm{Co}_{0.3} \mathrm{Ni}_{0.7} \mathrm{Fe}_{2} \mathrm{O}_{4} @ \mathrm{SiO}_{2}$ membrane, ${ }^{77}$ graphene nanosheet, ${ }^{78}$ ultrathin-shell BN hollow sphere, ${ }^{79}$ hollow octahedral carbon cage, ${ }^{71}$ hierarchical $\mathrm{WO}_{3}$ hydrate, ${ }^{80}$ holey graphene nanosheet, ${ }^{81}$ well-defined microporous carbon, ${ }^{73}$ polymer organic framework, ${ }^{82}$ graphene oxide- chitosan hydrogel, ${ }^{83}$ activated carbon, ${ }^{84}$ activated carbon nanotube, ${ }^{76}$ cobalt/nanoporous carbon particle, ${ }^{85}$ ordered mesoporous carbon, ${ }^{84}$ porous carbon nanosheet,$^{75}$ carbon nanofiber aerogel, ${ }^{86}$ and carbonaceous nanofiber ${ }^{87}$ NPCNS-10 shows the highest adsorption capacity of MB. Besides, from a synthetic point of view, NPCNS-10 possesses great advantages over previous adsorbents as no post-treatments (e.g., acid washing $)^{73}$ or activation steps (e.g., KOH activation) ${ }^{75,76}$ are involved. Additionally, optical photographs were taken before and after MB adsorption (Fig. $8 \mathrm{~b}$ and c). For instance, after the adsorption of $\mathrm{MB}$ with an initial concentration of $400 \mathrm{mg} \mathrm{L}^{-1}$ on the NPCNS-10, the model "polluted water" turns clear, affirming the efficient adsorption and distinct decolouration for tinctorial wastewater using NPCNS-10. In comparison, the equilibrium adsorption isotherms of MB on the NPCNS- 1 and NPCNS- 5 are illustrated in Fig. 8d. Similar to NPCNS-10, the adsorption isotherms of NPCNS- 1 and NPCNS- 5 belong to the type I curve, which is characteristic of the Langmuir isotherm. The $q_{\mathrm{m}}$ of NPCNS-1 and NPCNS-5 for MB (Table 3) is up to 798.7 and $818.2 \mathrm{mg} \mathrm{g}^{-1}$, respectively, lower than that of NPCNS-10.

The reusability of an adsorbent is essential to amplify its practical value. Herein, after the first run, NPCNS-10 was separated by centrifuge, washed with ethanol to desorb MB molecules and dried in a vacuum oven for its next use. Fig. 8e displays the adsorption performance of the reclaimed NPCNS10. The adsorption capacity of NPCNS-10 after 5 cycles is $935.0 \mathrm{mg} \mathrm{g}^{-1}$, which is approximately $97 \%$ of the original capacity $\left(962.1 \mathrm{mg} \mathrm{g}^{-1}\right)$. After 10 cycles, $93 \%$ of the original capacity remains. It further decreases slightly along more cycles (Fig. S10 $\dagger$ ). The lost adsorption capacity is caused by the incomplete MB desorption from the NPCNS-10 during regeneration, similar to previous reports. ${ }^{75,87}$ Nevertheless, these values are higher than most of the reported adsorbents (Table 4). Based on these results, it can be concluded that NPCNS-10 represents a new candidate with excellent performance to remove organic pollutants from wastewater.

Table 4 Comparison of the MB adsorption capacity among various adsorbents

\begin{tabular}{|c|c|c|c|}
\hline Entry & Adsorbent & Adsorption capacity $\left(\mathrm{mg} \mathrm{g}^{-1}\right)$ & Reference \\
\hline 1 & $\mathrm{Co}_{0.3} \mathrm{Ni}_{0.7} \mathrm{Fe}_{2} \mathrm{O}_{4} @ \mathrm{SiO}_{2}$ membrane & 107.5 & 77 \\
\hline 2 & Graphene nanosheet & 111.6 & 78 \\
\hline 4 & Hollow octahedral carbon cage & 198.9 & 71 \\
\hline 5 & Hierarchical $\mathrm{WO}_{3}$ hydrate & 247.3 & 80 \\
\hline 6 & Holey graphene nanosheet & 269 & 81 \\
\hline 9 & Graphene oxide-chitosan hydrogel & 390 & 83 \\
\hline 10 & Activated carbon & 396 & 84 \\
\hline 11 & Activated carbon nanotube & 400 & 76 \\
\hline 12 & Cobalt/nanoporous carbon particle & 500 & 85 \\
\hline 13 & Ordered mesoporous carbon & 758 & 84 \\
\hline 14 & Porous carbon nanosheet & 769 & 75 \\
\hline
\end{tabular}




\section{Conclusions}

In summary, we have successfully prepared NPCNSs using PIL as the precursor and $\mathrm{C}_{3} \mathrm{~N}_{4}$ nanosheets as sacrificial templates through a facile one-pot condensation approach. $\mathrm{C}_{3} \mathrm{~N}_{4}$ nanosheets are found to improve the yield and nitrogen content of NPCNSs and facilitate the formation of NPCNSs with unique included pore structures. The as-synthesized NPCNSs show a large specific surface area of $1120 \mathrm{~m}^{2} \mathrm{~g}^{-1}$ and a high nitrogen content of $17.4 \%$. More importantly, it is demonstrated that NPCNSs display not only a high $\mathrm{CO}_{2}$ adsorption capacity with outstanding reversibility, but also a very high methylene blue adsorption capacity of $962.1 \mathrm{mg} \mathrm{g}^{-1}$ (among the highest ever reported adsorption capacities in wastewater) with excellent reusability. It is believed that without post-treatments or activation steps, this work opens up a new exciting sustainable avenue to synthesize functional porous adsorption materials from PIL. Related experiments along with their use in catalysis and energy storage are currently ongoing in our laboratory.

\section{Acknowledgements}

This work was supported by the Max Planck Society. We would like to thank Prof. Tao Tang for the XPS measurements. J. Y. thanks the ERC (European Research Council) Starting Grant (project number 639720 - NAPOLI) for financial support.

\section{Notes and references}

1 X. Wang, X. Li, L. Zhang, Y. Yoon, P. K. Weber, H. Wang, J. Guo and H. Dai, Science, 2009, 324, 768-771.

2 H.-W. Liang, W. Wei, Z.-S. Wu, X. Feng and K. Müllen, J. Am. Chem. Soc., 2013, 135, 16002-16005.

3 J. P. Paraknowitsch, J. Zhang, D. Su, A. Thomas and M. Antonietti, Adv. Mater., 2010, 22, 87-92.

4 T.-P. Fellinger, A. Thomas, J. Yuan and M. Antonietti, Adv. Mater., 2013, 25, 5838-5855.

5 X.-H. Li, S. Kurasch, U. Kaiser and M. Antonietti, Angew. Chem., Int. Ed., 2012, 51, 9689-9692.

6 X. Liu and M. Antonietti, Adv. Mater., 2013, 25, 6284-6290.

7 J. S. Lee, X. Wang, H. Luo and S. Dai, Adv. Mater., 2010, 22, 1004-1007.

8 X. Wang and S. Dai, Angew. Chem., Int. Ed., 2010, 49, 66646668.

9 K. Gong, F. Du, Z. Xia, M. Durstock and L. Dai, Science, 2009, 323, 760-764.

10 T.-P. Fellinger, F. Hasché, P. Strasser and M. Antonietti, J. Am. Chem. Soc., 2012, 134, 4072-4075.

11 X. Xu, Y. Li, Y. Gong, P. Zhang, H. Li and Y. Wang, J. Am. Chem. Soc., 2012, 134, 16987-16990.

12 K. Parvez, S. Yang, Y. Hernandez, A. Winter, A. Turchanin, X. Feng and K. Müllen, ACS Nano, 2012, 6, 9541-9550.

13 Y. Gao, G. Hu, J. Zhong, Z. Shi, Y. Zhu, D. S. Su, J. Wang, X. Bao and D. Ma, Angew. Chem., Int. Ed., 2013, 52, 21092113.

14 X. Xu, S. Jiang, Z. Hu and S. Liu, ACS Nano, 2010, 4, 42924298.
15 M. C. Gutiérrez, D. Carriazo, C. O. Ania, J. B. Parra, M. L. Ferrer and F. del Monte, Energy Environ. Sci., 2011, 4, 3535-3544.

16 J. Patiño, M. C. Gutiérrez, D. Carriazo, C. O. Ania, J. B. Parra, M. L. Ferrer and F. del Monte, Energy Environ. Sci., 2012, 5, 8699-8707.

17 N. López-Salas, M. C. Gutiérrez, C. O. Ania, J. L. G. Fierro, M. L. Ferrer and F. del Monte, J. Mater. Chem. A, 2014, 2, 17387-17399.

18 S. J. Yang, M. Antonietti and N. Fechler, J. Am. Chem. Soc., 2015, 137, 8269-8273.

19 L. Zhao, L.-Z. Fan, M.-Q. Zhou, H. Guan, S. Qiao, M. Antonietti and M.-M. Titirici, Adv. Mater., 2010, 22, 5202-5206.

20 S. Zhang, M. S. Miran, A. Ikoma, K. Dokko and M. Watanabe, J. Am. Chem. Soc., 2014, 136, 1690-1693.

21 G.-L. Tian, Q. Zhang, B. Zhang, Y.-G. Jin, J.-Q. Huang, D. S. Su and F. Wei, Adv. Funct. Mater., 2014, 24, 5956-5961.

22 Y. Zhu, B. Zhang, X. Liu, D.-W. Wang and D. S. Su, Angew. Chem., Int. Ed., 2014, 53, 10673-10677.

23 J. Wei, D. Zhou, Z. Sun, Y. Deng, Y. Xia and D. Zhao, Adv. Funct. Mater., 2013, 23, 2322-2328.

24 Z. Jin, J. Yao, C. Kittrell and J. M. Tour, ACS Nano, 2011, 5, 4112-4117.

25 L. Lai, J. R. Potts, D. Zhan, L. Wang, C. K. Poh, C. Tang, H. Gong, Z. Shen, J. Lin and R. S. Ruoff, Energy Environ. Sci., 2012, 5, 7936-7942.

26 L. L. Zhang, X. Zhao, H. Ji, M. D. Stoller, L. Lai, S. Murali, S. Mcdonnell, B. Cleveger, R. M. Wallace and R. S. Ruoff, Energy Environ. Sci., 2012, 5, 9618-9625.

27 P. Chen, L.-K. Wang, G. Wang, M.-R. Gao, J. Ge, W.-J. Yuan, Y.-H. Shen, A.-J. Xie and S.-H. Yu, Energy Environ. Sci., 2014, 7, 4095-4103.

28 X. Ma, Y. Li, M. Cao and C. Hu, J. Mater. Chem. A, 2014, 2, 4819-4826.

29 D. Hulicova-Jurcakova, A. M. Puziy, O. I. Poddubnaya, F. Suárez-García, J. M. D. Tascón and G. Q. Lu, J. Am. Chem. Soc., 2009, 131, 5026-5027.

30 V. Chandra, S. U. Yu, S. H. Kim, Y. S. Yoon, D. Y. Kim, A. H. Kwon, M. Meyyappan and K. S. Kim, Chem. Commun., 2012, 48, 735-737.

31 M. Sevilla, P. Valle-Vigón and A. B. Fuertes, Adv. Funct. Mater., 2011, 21, 2781-2787.

32 L. Qie, W.-M. Chen, Z.-H. Wang, Q.-G. Shao, X. Li, L.-X. Yuan, X.-L. Hu, W.-X. Zhang and Y.-H. Huang, Adv. Mater., 2012, 24, 2047-2050.

33 G.-P. Hao, W.-C. Li, D. Qian, G.-H. Wang, W.-P. Zhang, T. Zhang, A.-Q. Wang, F. Schüth, H.-J. Bongard and A.-H. Lu, J. Am. Chem. Soc., 2011, 133, 11378-11388.

34 M. Nandi, K. Okada, A. Dutta, A. Bhaumik, J. Maruyama, D. Derks and H. Uyama, Chem. Commun., 2012, 48, 1028310285.

35 Y. Xia and R. Mokaya, Adv. Mater., 2004, 16, 1553-1558.

36 Y. Zhao, X. Liu, K. X. Yao, L. Zhao and Y. Han, Chem. Mater., 2012, 24, 4725-4734.

37 B. Qiu, C. Pan, W. Qian, Y. Peng, L. Qiu and F. Yan, J. Mater. Chem. A, 2013, 1, 6373-6378. 
38 Á. Sánchez-Sánchez, F. Suárez-García, A. Martínez-Alonso and J. M. D. Tascón, ACS Appl. Mater. Interfaces, 2014, 6, 21237-21247.

39 C. Zhang, M. Antonietti and T.-P. Fellinger, Adv. Funct. Mater., 2014, 24, 7655-7665.

40 L. Liu, Q.-F. Deng, T.-Y. Ma, X.-Z. Lin, X.-X. Hou, Y.-P. Liu and Z.-Y. Yuan, J. Mater. Chem., 2011, 21, 16001-16009.

41 Y. Xia, R. Mokaya, G. S. Walker and Y. Zhu, Adv. Energy Mater., 2011, 1, 678-683.

42 J. Yuan, C. Giordano and M. Antonietti, Chem. Mater., 2010, 22, 5003-5012.

43 J. Yuan, D. Mecerreyes and M. Antonietti, Prog. Polym. Sci., 2013, 38, 1009-1036.

44 S. Zhang, K. Dokko and M. Watanabe, Chem. Sci., 2015, 6, 3684-3691.

45 J. Gong, B. Michalkiewicz, X. Chen, E. Mijowska, J. Liu, Z. Jiang, X. Wen and T. Tang, ACS Sustainable Chem. Eng., 2014, 2, 2837-2844.

46 J. Gong, K. Yao, J. Liu, Z. Jiang, X. Chen, X. Wen, E. Mijowska, N. Tian and T. Tang, J. Mater. Chem. A, 2013, 1, 5247-5255.

47 S. Soll, T.-P. Fellinger, X. Wang, Q. Zhao, M. Antonietti and J. Yuan, Small, 2013, 9, 4135-4141.

48 D. Kuzmicz, S. Prescher, F. Polzer, S. Soll, C. Seitz, M. Antonietti and J. Yuan, Angew. Chem., Int. Ed., 2014, 53, 1062-1066.

49 Q. Zhao, T.-P. Fellinger, M. Antonietti and J. Yuan, J. Mater. Chem. A, 2013, 1, 5113-5120.

50 J. Yuan, A. G. Márquez, J. Reinacher, C. Giordano, J. Janek and M. Antonietti, Polym. Chem., 2011, 2, 1654-1657.

51 Y. Men, M. Siebenbürger, X. Qiu, M. Antonietti and J. Yuan, J. Mater. Chem. A, 2013, 1, 11887-11893.

52 M. Ambrogi, K. Täuber, M. Antonietti and J. Yuan, J. Mater. Chem. A, 2015, 3, 5778-5782.

53 M. Rose, Y. Korenblit, E. Kockrick, L. Borchardt, M. Oschatz, S. Kaskel and G. Yushin, Small, 2011, 7, 1108-1117.

54 X. Zheng, J. Luo, W. Lv, D.-W. Wang and Q.-H. Yang, Adv. Mater., 2015, 27, 5388-5395.

55 C. Tang, B.-Q. Li, Q. Zhang, L. Zhu, H.-F. Wang, J.-L. Shi and F. Wei, Adv. Funct. Mater., 2016, 26, 577-585.

56 C. Li, M. Wei, D. G. Evans and X. Duan, Small, 2014, 10, 4469-4486.

57 H. Zhu, D. Chen, W. An, N. Li, Q. Xu, H. Li, J. He and J. Lu, Small, 2015, 11, 5222-5229.

58 B. Hu, K. Wang, L. Wu, S.-H. Yu, M. Antonietti and M.-M. Titirici, Adv. Mater., 2010, 22, 813-828.

59 S. Biswas, T. Rémy, S. Couck, D. Denysenko, G. Rampelberg, J. F. M. Denayer, D. Volkmer, C. Detavernier and P. Van Der Voort, Phys. Chem. Chem. Phys., 2013, 15, 3552-3561.

60 J. Wang, L. Huang, R. Yang, Z. Zhang, J. Wu, Y. Gao, Q. Wang, D. O'Hare and Z. Zhong, Energy Environ. Sci., 2014, 7, 3478-3518.

61 Q. Zhao, J. W. C. Dunlop, X. Qiu, F. Huang, Z. Zhang, J. Heyda, J. Dzubiella, M. Antonietti and J. Yuan, Nat. Commun., 2014, 5, 4293.

62 X. Wang, K. Maeda, A. Thomas, K. Takanabe, G. Xin, J. M. Carlsson, K. Domen and M. Antonietti, Nat. Mater., 2009, 8, 76-80.
63 A.-H. Lu, E. L. Salabas and F. Schüth, Angew. Chem., Int. Ed., 2007, 46, 1222-1244.

64 Y.-L. Ding, P. Kopold, K. Hahn, P. A. van Aken, J. Maier and Y. Yu, Adv. Funct. Mater., 2016, 26, 1112.

65 J. S. Lee, X. Wang, H. Luo, G. A. Baker and S. Dai, J. Am. Chem. Soc., 2009, 131, 4596-4597.

66 J. Wang, I. Senkovska, M. Oschatz, M. R. Lohe, L. Borchardt, A. Heerwig, Q. Liu and S. Kaskel, ACS Appl. Mater. Interfaces, 2013, 5, 3160-3167.

67 D. L. Sivadas, R. Narasimman, R. Rajeev, K. Prabhakaran and K. N. Ninan, J. Mater. Chem. A, 2015, 3, 16213-16221.

68 Q. Chen, D.-P. Liu, M. Luo, L.-J. Feng, Y.-C. Zhao and B.-H. Han, Small, 2014, 10, 308-315.

69 R. Du, N. Zhang, H. Xu, N. Mao, W. Duan, J. Wang, Q. Zhao, Z. Liu and J. Zhang, Adv. Mater., 2014, 26, 8053-8058.

70 N. Huang, X. Chen, R. Krishna and D. Jiang, Angew. Chem., Int. Ed., 2015, 54, 2986-2990.

71 A. Aijaz, J.-K. Sun, P. Pachfule, T. Uchida and Q. Xu, Chem. Commun., 2015, 51, 13945-13948.

72 S. Couck, Y.-Y. Liu, K. Leus, G. V. Baron, P. Van der Voort and J. F. M. Denayer, Microporous Mesoporous Mater., 2015, 206, 217-225.

73 Z. Li, D. Wu, Y. Liang, R. Fu and K. Matyjaszewski, J. Am. Chem. Soc., 2014, 136, 4805-4808.

74 G.-P. Hao, Z.-Y. Jin, Q. Sun, X.-Q. Zhang, J.-T. Zhang and A.-H. Lu, Energy Environ. Sci., 2013, 6, 3740-3747.

75 J. Gong, J. Liu, X. Chen, Z. Jiang, X. Wen, E. Mijowska and T. Tang, J. Mater. Chem. A, 2015, 3, 341-351.

76 J. Ma, F. Yu, L. Zhou, L. Jin, M. Yang, J. Luan, Y. Tang, H. Fan, Z. Yuan and J. Chen, ACS Appl. Mater. Interfaces, 2012, 4, 5749-5760.

77 Z. Zhu, G. Li, G. Zeng, X. Chen, D. Hu, Y. Zhang and Y. Sun, J. Mater. Chem. A, 2015, 3, 22000-22004.

78 Z.-J. Fan, W. Kai, J. Yan, T. Wei, L.-J. Zhi, J. Feng, Y.-M. Ren, L.-P. Song and F. Wei, ACS Nano, 2011, 5, 191-198.

79 G. Lian, X. Zhang, S. J. Zhang, D. Liu, D. L. Cui and Q. L. Wang, Energy Environ. Sci., 2012, 5, 7072-7080.

80 B. Liu, J. Wang, J. Wu, H. Li, Z. Li, M. Zhou and T. Zuo, J. Mater. Chem. A, 2014, 2, 1947-1954.

81 Z. Xing, J. Tian, Q. Liu, A. M. Asiri, P. Jiang and X. Sun, Nanoscale, 2014, 6, 11659-11663.

82 P. Kuhn, K. Krüger, A. Thomas and M. Antonietti, Chem. Commun., 2008, 100, 5815-5817.

83 Y. Chen, L. Chen, H. Bai and L. Li, J. Mater. Chem. A, 2013, 1, 1992-2001.

84 X. Zhuang, Y. Wan, C. Feng, Y. Shen and D. Zhao, Chem. Mater., 2009, 21, 706-716.

85 N. L. Torad, M. Hu, S. Ishihara, H. Sukegawa, A. A. Belik, M. Imura, K. Ariga, Y. Sakka and Y. Yamauchi, Small, 2014, 10, 2096-2107.

86 H.-W. Liang, Q.-F. Guan, L.-F. Chen, Z. Zhu, W.-J. Zhang and S.-H. Yu, Angew. Chem., Int. Ed., 2012, 124, 5191-5195.

87 H.-W. Liang, X. Cao, W.-J. Zhang, H.-T. Lin, F. Zhou, L.-F. Chen and S.-H. Yu, Adv. Funct. Mater., 2011, 21, 38513858 . 